\title{
Is subvalvular repair worthwhile in severe ischemic mitral regurgitation? Subanalysis of the Papillary Muscle Approximation trial
}

Francesco Nappi, MD, ${ }^{\mathrm{a}, \mathrm{b}}$ Cristiano Spadaccio, MD, PhD,${ }^{\mathrm{a}, \mathrm{c}}$ Antonio Nenna, MD, ${ }^{\mathrm{a}}$ Mario Lusini, MD, PhD, ${ }^{\mathrm{a}}$ Massimiliano Fraldi, $\mathrm{PhD},{ }^{\mathrm{d}}$ Christophe Acar, $\mathrm{MD},{ }^{\mathrm{e}}$ and Massimo Chello, $\mathrm{MD}^{\mathrm{a}}$

\begin{abstract}
Objective: The symmetry of mitral valve tethering and regional left ventricle wall dysfunction are reported to play a fundamental role in the outcomes and long-term durability of surgical repair in ischemic mitral regurgitation (IMR). We recently demonstrated in a randomized clinical trial (the Papillary Muscle Approximation trial) the superiority of papillary muscle approximation (PMA) in combination with standard restrictive annuloplasty (RA) in severe IMR over annuloplasty alone in terms of adverse left ventricular remodeling and mitral regurgitation (MR) recurrence. This approach, however, failed to produce a survival advantage and was still plagued by a high incidence of reoperation. We therefore performed a subanalysis of the PMA trial on the basis of preoperative parameters to elucidate the value of subvalvular surgery in certain subcategories of patients with the aim of creating a decisional algorithm on the best operative strategy.
\end{abstract}

Methods: We performed a subanalysis of PMA trial, evaluating 96 patients with severe IMR and eligible for myocardial revascularization randomized to PMA + RA $(n=48)$ versus RA alone $(n=48)$ in association with coronary artery bypass grafting. Endpoints included left ventricular remodeling, MR recurrence, overall mortality, reoperation, and a composite cardiac endpoint (cardiac death, stroke, reintervention, hospitalization for heart failure, or New York Heart Association class worsening). Stratification variables were preoperative symmetry of mitral valve tethering and regional wall motion abnormality.

Results: PMA improved ventricular remodeling and recurrence of MR in both preoperative symmetric and asymmetric tethering and in case of inferior wall dyskinesia but did not produce an additional benefit in anterolateral wall dysfunction.

Conclusions: Preoperative symmetric and asymmetric tethering and isolated inferior wall dyskinesia are an indication for subvalvular apparatus surgery in IMR. (J Thorac Cardiovasc Surg 2017;153:286-95)

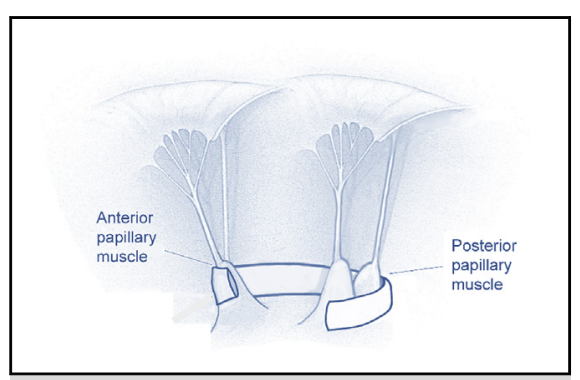

Papillary muscle approximation.

\section{Central Message}

Papillary muscle approximation might be indicated in case of both symmetric and asymmetric tethering in ischemic mitral regurgitation.

\section{Perspective}

The addition of papillary muscle approximation to restrictive annuloplasty and complete myocardial revascularization is associated with better left ventricular remodeling. Considering the importance of tethering and wall motion abnormalities, a tailored approach is crucial for satisfactory long-term outcomes. A deeper knowledge of the geometric problem would profoundly impact the decision algorithm.

See Editorial Commentary page 296.

See Editorial page 284 .
From the a Department of Cardiovascular Surgery, Università Campus Bio-Medico di Roma, Rome; ' Department of Cardiac Surgery, Centre Cardiologique du Nord de Saint-Denis; ' ${ }^{\mathrm{D}}$ Department of Cardiothoracic Surgery, Golden Jubilee National Hospital, Glasgow, United Kingdom; ${ }^{\mathrm{d}}$ Department of Structures for Engineering and Architecture and Interdisciplinary Research Center for Biomaterials, Università di Napoli “Federico II," Naples, Italy; and 'Department of Cardiac Surgery, Hopital La Pitie Salpetriere, Paris, France.

Drs F.N. and C.S. contributed equally to this work.

Read at the 96th Annual Meeting of The American Association for Thoracic Surgery, May 14-18, 2016, Baltimore, Maryland.

Received for publication April 26, 2016; revisions received Sept 15, 2016; accepted for publication Sept 16, 2016; available ahead of print Oct 20, 2016.

Address for reprints: Francesco Nappi, MD, Cardiac Surgery, Centre Cardiologique du Nord de Saint-Denis, 36 Rue des Moulins Gémeaux, 93200 Saint-Denis, France (E-mail: francesconappi2@gmail.com).

0022-5223/\$36.00

Copyright (c) 2016 by The American Association for Thoracic Surgery

http://dx.doi.org/10.1016/j.jtcvs.2016.09.050
Treatment of ischemic mitral regurgitation (IMR) is a complex surgical problem and still a matter of debate. ${ }^{1,2}$ In a randomized clinical trial (the Papillary Muscle Approximation [PMA] trial), papillary muscle approximation (PMA) in addition to undersizing restrictive annuloplasty (RA) associated with complete

Scanning this QR code will take you to the supplemental figures, tables, and video for this article. 


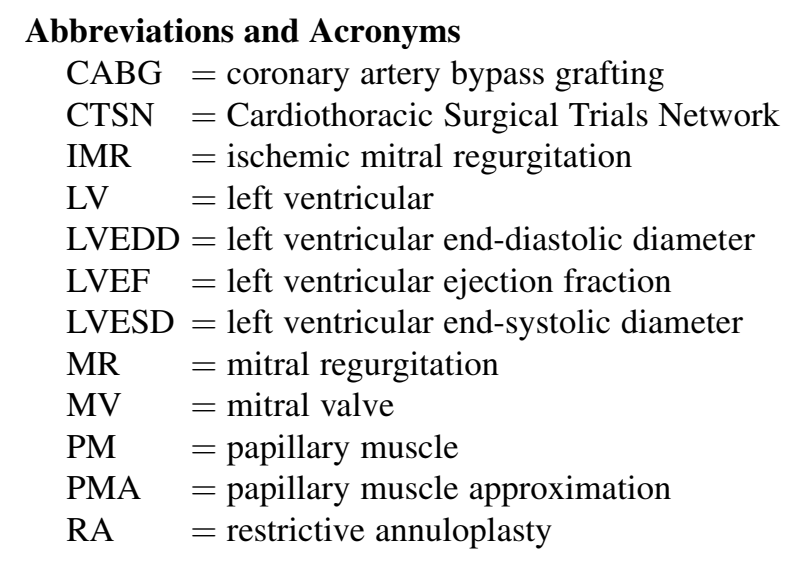

myocardial revascularization using coronary artery bypass grafting $(\mathrm{CABG})$ exerted a long-term beneficial effect on left ventricular (LV) remodeling and a more effective restoration of mitral valve (MV) configuration ${ }^{1}$; however, despite the improved cardiac outcomes, this approach failed to produce a difference in overall mortality and functional status. $^{1}$

Several investigators established a relationship to determine the equilibrium between closing and tethering forces at the level of the annulus and the subvalvular apparatus ${ }^{3-5}$ contributing to the further development of long-term adverse LV remodeling. ${ }^{6,7}$ In our trial, we confirm that the real "Achilles heel" of MV repair in IMR is the LV remodeling and the complete understanding of its bases. Moreover, regional motion abnormalities and dyssynchronies ${ }^{8,9}$ and preoperative features of MV tethering ${ }^{10-13}$ have been claimed as fundamental predictors of the outcomes of the repair to identify categories of patients who may benefit from specific reparative approaches. $6,7,14,15$

We therefore reviewed the results of the PMA trial to evaluate the symmetry of the tethering and wall motion abnormalities in defining the outcomes of PMA or RA. This study addresses the question about the effects of the subvalvular approach in specific categories of patients with the final aim of orienting the surgical decision on the best approach for each type of IMR.

\section{PATIENTS AND METHODS \\ Study Design}

This study is a subanalysis of a recently published prospective randomized trial, thereafter mentioned as the PMA trial (Video 1), ${ }^{1}$ which evaluated 96 patients with severe chronic IMR who underwent complete surgical myocardial revascularization associated with either isolated undersizing RA (RA group) or PMA and undersizing RA (PMA group) over a 5-year follow-up. Patients were included in the study if they had symptomatic and severe IMR, were unresponsive to medical therapy, and had significant coronary artery disease eligible for surgical revascularization with no previously performed percutaneous procedures. The detailed description of sample size definition and power analysis, enrollment criteria, follow-up method, and results is discussed in the cited paper. ${ }^{1}$

\section{Echocardiographic Evaluation}

The severity of IMR was evaluated by means of transthoracic echocardiography performed with criteria recommended by the European Society of Echocardiography. ${ }^{16}$ All echocardiographic measurements were assessed by 2 independent experienced cardiologists, blinded in regard to the treatment group. Severe mitral regurgitation (MR) was defined as an effective regurgitant orifice area of at least $0.4 \mathrm{~cm}^{2}$ or by a combination of adjunctive echocardiographic quantification methods according to the guidelines. 1,16

\section{Interventions}

The surgery was performed through a median sternotomy under normotermic cardiopulmonary bypass conditions and intermittent anterograde blood cardioplegia. Before we established the cardiopulmonary bypass, transesophageal echocardiography was performed to confirm the absence of MV structural abnormalities and the patient's eligibility for the study. End-diastolic and end-systolic interpapillary distances were compared with preoperative values measured via transthoracic echocardiography.

The MV was exposed through a left atriotomy with the support of a Carpentier retractor (Tisurg, Jiangsu, People's Republic of China). Leaflets restriction as the result of excess traction on the leaflets leading to a lack of coaptation was diagnosed in all patients. The papillary muscles (PMs) were identified through the MV orifice in each patient and inspected carefully. The PMs were classified anatomically as type I and II were approximated with a CV-4 Gore-Tex suture (W. L. Gore \& Associates, Flagstaff, Ariz) placed at the head of each PM (Figure 1, A). Considering type III, IV, or V PMs, their approximation was performed with a 4-mm Gore-Tex tube (W. L. Gore \& Associates) encircling the bodies of posteromedial and anterolateral PMs, which were drawn together (Figure 1, B). In the presence of 2 independent heads, both posteromedial PMs were approximated to minimize MV tenting.

Particular care was taken in the evaluation of chordal organization and to adequately correct regurgitation. Normally, posteromedial PM gives rise to chordae for scallop P2 and P3 of the posterior leaflet, whereas from anterolateral PMs spring out the chordae to anterior leaflet, which are involved

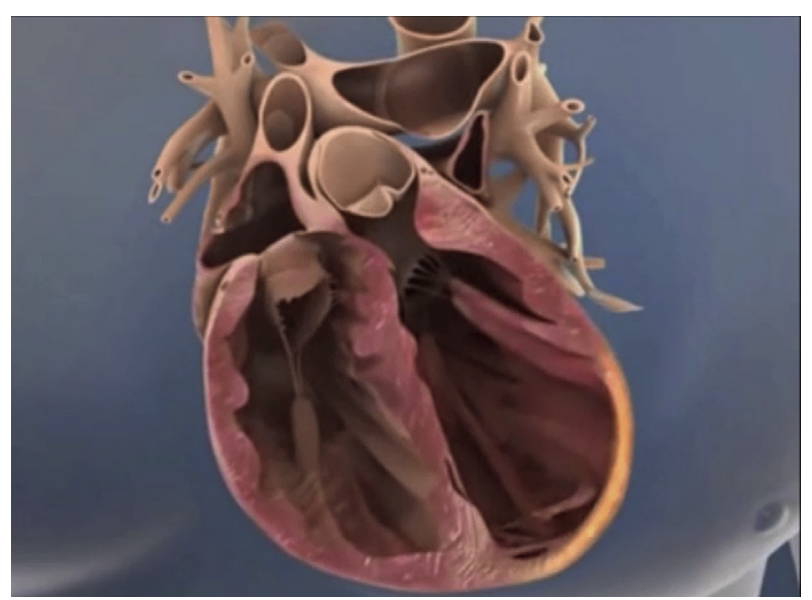

VIDEO 1. Animation showing the rationale and basic principles of papillary muscle approximation. The video also explains some surgical technicalities inherent in the surgical procedure according to the variability of papillary muscle morphology and anatomy. Video available at: http:// www.jtcvsonline.org/article/S0022-5223(16)31168-0/addons. 


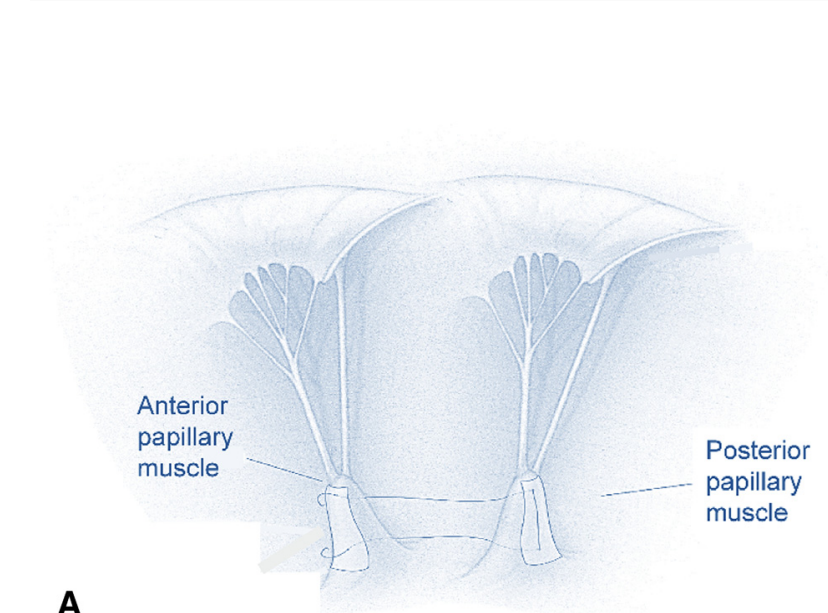

A

\section{B}

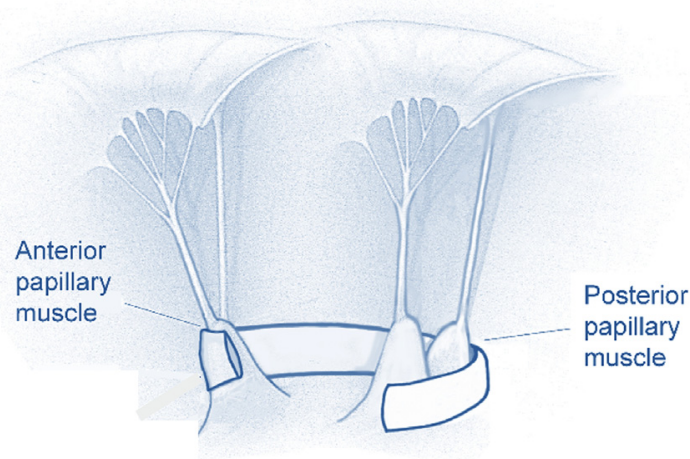

FIGURE 1. Papillary muscle approximation procedure depending on surgical anatomy of papillary muscles: anatomy type 1 or 2 (A), or type 3,4 , or 5 (B).

mainly in development of the "seagull sign" and respective tenting. The intraoperative goal was to achieve a PMA with a reduction of about $25 \%$ to $30 \%$ in the end-diastolic interpapillary distance compared with the preoperative value, confirmed via the use of intraoperative transesophageal echocardiography.

After diastolic cardioplegic arrest, intraoperative interpapillary distance was measured with a flax thread to confirm the echocardiographic findings; therefore, PM distance was reduced and a second measurement was performed by the same method to confirm the result. The anterior leaflet area was calibrated with a prosthetic ring obturator and with a 2-sizes undersizing annuloplasty performed with a Carpentier-Edwards Physio Annuloplasty Ring (Edwards Lifesciences, Irving, Calif) The prosthetic ring was fixed with the use of $2 / 0$ braided sutures placed $1 \mathrm{~mm}$ away from the leaflet's hinge on the atrial wall. Sutures were placed circumferentially starting as usual at the level of the posterior commissural area in counterclockwise fashion. Larger bites were used at the posterior part of the annulus from trigone to trigone to accentuate the downsizing effect at this level. All sutures were then passed through the prosthetic ring cuff. The ring was lowered into position and the sutures were tied. Concomitant CABG was performed in all patients, with complete revascularization of the diseased coronary arteries.

\section{Endpoints}

The primary endpoint of the trial was the evaluation of LV remodeling, measured as the left ventricular end diastolic diameter (LVEDD) absolute difference from baseline, during a 5-year follow-up period. Secondary endpoints included changes in other echocardiographic parameters, overall mortality, reoperation, and a composite cardiac endpoint (cardiac death, stroke, reintervention, hospitalization for heart failure, or New York Heart
Association class worsening). After regression analysis (Table E1), the only preoperative variables found to significantly predict the primary endpoint were symmetry of MV tethering and regional wall motion abnormality. Therefore, the discussed subgroup analysis was performed according to these 2 variables.

\section{Statistical Analysis}

Variables included in this study were chosen after a linear regression analysis in which we considered all variables that might have affected the outcomes: the primary endpoint of the study (LVEDD absolute difference at 5 years from baseline) has been considered as the dependent variable, whereas other variables have been evaluated after adjustment for treatment group (PMA vs RA). Variables with a $P$ value less than .200 were considered for this subanalysis (Table E1).

Categorical data are displayed as frequencies and percentages in text and tables, and comparisons were made with the $\chi^{2}$ test. Normality criteria were checked and met for each continuous variable. Independent sample or paired sample $t$-test was used for normally distributed data, which are presented as mean \pm standard deviation in text and tables. Survival analysis was performed with the Kaplan-Meier method and log-rank test was used to compare survival functions.

As the result of logistic reasons, echocardiographic evaluations were performed at our Center only preoperatively and 1,2, and 5 years after the surgical procedure. Other periodical assessments were performed elsewhere and were reviewed during the outpatient visit. To verify the results of the long-term outcome considering the intermediate time points, a longitudinal mixed model has been built that includes the echocardiographic parameters obtained from our Center's evaluation. We did not include other third-party echocardiographic evaluations in this model, which might have produced unreliable results. The longitudinal model evaluated in the subgroups obtained from the linear regression analysis, the LVEDD, left ventricular end-systolic diameter (LVESD), and left ventricular ejection fraction (LVEF), after adjustment for preoperative values, which were regarded as baseline. The PMA group effect depending on the symmetry of tethering or regional wall motion abnormalities, expressed as unit change per year after surgery, is presented in Table E2. Those results do not differ conceptually from the findings of the end-ofthe-study analysis discussed in the manuscript.

A $P$ value less than .05 was considered statistically significant. Statistical analysis was performed with STATA Statistics version 13 (StataCorp LP, College Station, Tex).

\section{RESULTS}

Baseline characteristics, echocardiographic findings, and survival analysis of the whole cohort of enrolled patients has been published elsewhere. ${ }^{1}$ In the PMA group, end-systolic interpapillary distance decreased from a preoperative value of $40.5 \pm 4.6 \mathrm{~mm}$ (transthoracic echocardiogram) to an intraoperative value of $32.7 \pm 3.2 \mathrm{~mm}$ (transesophageal echocardiogram), with a mean difference of $6.8 \pm 3.1(P<.001)$. End-diastolic interpapillary distance was reduced from $44.7 \pm 4.2 \mathrm{~mm}$ to $36.0 \pm 3.7 \mathrm{~mm}$, with a mean difference of $9.3 \pm 1.5(P<.001)$. Preoperative evaluation, surgical details, and tethering and regional wall motion features were similar between groups and are shown in Table 1.

\section{Early Outcomes}

In-hospital deaths for the entire population occurred in 3 patients $(6.2 \%)$ in the RA group and in 2 patients $(4.2 \%)$ in 
TABLE 1. Baseline characteristics

\begin{tabular}{|c|c|c|c|}
\hline & $\begin{array}{l}\text { RA group } \\
(N=48)\end{array}$ & $\begin{array}{l}\text { PMA group } \\
(\mathbf{N}=\mathbf{4 8})\end{array}$ & $\begin{array}{c}P \\
\text { value }\end{array}$ \\
\hline Male sex & $30(62.5)$ & $28(58.3)$ & .676 \\
\hline Age, y & $64.6 \pm 7.4$ & $62.9 \pm 7.0$ & .310 \\
\hline NYHA functional class & & & .496 \\
\hline 3 & $12(25.0)$ & $15(31.2)$ & \\
\hline 4 & $36(75.0)$ & $33(68.7)$ & \\
\hline Grade on CCS angina scale, $n(\%)$ & & & .834 \\
\hline No angina & $29(60.4)$ & $30(62.5)$ & \\
\hline Grade III or IV & $19(39.6)$ & $18(37.5)$ & \\
\hline Surgical procedure & & & .563 \\
\hline Within $60 \mathrm{~d}$ from infarction & $40(83.3)$ & $42(87.5)$ & \\
\hline More than $60 \mathrm{~d}$ from infarction & $8(17.7)$ & $6(12.5)$ & \\
\hline \multicolumn{4}{|l|}{ Cardiac comorbidities } \\
\hline Hypertension & $23(47.9)$ & $23(47.9)$ & 1.000 \\
\hline Dyslipidemia & $20(41.7)$ & $18(37.5)$ & .676 \\
\hline Diabetes & $20(41.7)$ & $18(37.5)$ & .676 \\
\hline $\begin{array}{l}\text { Familiarity for cardiovascular } \\
\text { disease }\end{array}$ & $12(25.0)$ & $12(25.0)$ & 1.000 \\
\hline Atrial fibrillation & $10(20.8)$ & $9(18.7)$ & .798 \\
\hline Smokers & $14(29.2)$ & $13(27.1)$ & .820 \\
\hline \multicolumn{4}{|l|}{ Noncardiac comorbidities } \\
\hline Chronic kidney disease stage III & $11(22.9)$ & $12(25.0)$ & .811 \\
\hline $\begin{array}{l}\text { Chronic obstructive pulmonary } \\
\text { disease }\end{array}$ & $6(12.5)$ & $7(14.6)$ & .827 \\
\hline Carotid disease & $3(6.2)$ & $4(8.3)$ & .695 \\
\hline Previous stroke & $2(4.2)$ & $2(4.2)$ & 1.000 \\
\hline \multicolumn{4}{|l|}{ Preoperative medications } \\
\hline Beta-blockers & $40(83.3)$ & $41(85.4)$ & .779 \\
\hline Calcium-channel blockers & $23(48.9)$ & $26(54.2)$ & .610 \\
\hline Nitrates & $31(64.6)$ & $29(60.4)$ & .673 \\
\hline $\begin{array}{l}\text { Angiotensin-converting } \\
\text { enzyme inhibitors }\end{array}$ & $40(83.3)$ & $39(81.2)$ & .789 \\
\hline Angiotensin receptor blockers & $8(16.7)$ & $9(18.7)$ & .789 \\
\hline Diuretics & $48(100.0)$ & $48(100.0)$ & 1.000 \\
\hline Regional wall motion abnormality & & & .948 \\
\hline Inferior & $29(60.4)$ & $29(60.4)$ & \\
\hline Inferoposterior & $10(20.8)$ & $11(22.9)$ & \\
\hline Anterolateral & 9 (18.7) & $8(16.7)$ & \\
\hline Symmetric tethering & $18(37.5)$ & $19(39.6)$ & .834 \\
\hline \multicolumn{4}{|l|}{ Displacement (vector) } \\
\hline Lateral & $9(50.0)$ & $11(57.9)$ & \\
\hline Apical & $9(50.0)$ & $8(42.1)$ & \\
\hline \multicolumn{4}{|l|}{ Regional wall motion abnormality } \\
\hline Inferior & $2(11.1)$ & $1(5.3)$ & \\
\hline Inferoposterior & $7(38.9)$ & $11(57.9)$ & \\
\hline Anterolateral & $9(50.0)$ & $7(36.8)$ & \\
\hline Asymmetric tethering & $30(62.5)$ & $29(60.4)$ & .834 \\
\hline \multicolumn{4}{|l|}{ Displacement (vector) } \\
\hline Posterior & $30(100.0)$ & $29(100.0)$ & \\
\hline \multicolumn{4}{|l|}{ Regional wall motion abnormality } \\
\hline Inferior & $27(90.0)$ & $28(96.5)$ & \\
\hline Inferoposterior & $3(10.0)$ & $0(0.0)$ & \\
\hline Anterolateral & $0(0.0)$ & $1(3.5)$ & \\
\hline \multicolumn{4}{|l|}{ Surgical data } \\
\hline $\mathrm{CABG}, \mathrm{n}$ & $48(100)$ & $48(100)$ & 1.000 \\
\hline
\end{tabular}

TABLE 1. Continued

\begin{tabular}{|c|c|c|c|}
\hline & $\begin{array}{l}\text { RA group } \\
(\mathbf{N}=48)\end{array}$ & $\begin{array}{l}\text { PMA group } \\
(N=48)\end{array}$ & $\begin{array}{c}P \\
\text { value }\end{array}$ \\
\hline Number of grafts & & & .643 \\
\hline 1 & $12(25.0)$ & $12(25.0)$ & \\
\hline 2 & $4(8.3)$ & $2(4.2)$ & \\
\hline 3 & $17(35.4)$ & $14(29.2)$ & \\
\hline 4 & $15(31.2)$ & $20(41.7)$ & \\
\hline Mean & $2.7 \pm 1.2$ & $2.9 \pm 1.2$ & .549 \\
\hline Internal mammary artery & & & .904 \\
\hline 0 & $4(8.3)$ & $4(8.3)$ & \\
\hline 1 & $16(33.3)$ & $14(29.2)$ & \\
\hline 2 & $28(58.3)$ & $30(62.5)$ & \\
\hline Undersizing annuloplasty, $\mathrm{n} \%$ & $48(100)$ & $48(100)$ & 1.000 \\
\hline Ring size used & & & .536 \\
\hline $\begin{array}{l}\text { Physio annuloplasty } \\
\text { ring no. } 26, \mathrm{n}(\%)\end{array}$ & $19(39.6)$ & $22(45.8)$ & \\
\hline $\begin{array}{l}\text { Physio annuloplasty } \\
\text { ring no. } 28, \mathrm{n}(\%)\end{array}$ & $29(60.4)$ & $26(54.2)$ & \\
\hline AXC time, $\min$ & $93.4 \pm 6.3$ & $100.8 \pm 9.9$ & $<.001$ \\
\hline CPB time, $\min$ & $108.1 \pm 8.4$ & $116.3 \pm 9.2$ & $<.001$ \\
\hline
\end{tabular}

the PMA group, without a statistically significant difference between groups $(P=.646)$.

\section{Late Mortality and Outcomes}

Preoperative LVEDD was $61.4 \pm 3.7$ in the RA group and $62.7 \pm 3.4$ in the PMA group. The assessment of LVEDD at 5 years showed a significant between-group difference compared with the preoperative value; LVEDD was $56.5 \pm 5.7 \mathrm{~mm}$ in PMA group versus $60.6 \pm 4.6 \mathrm{~mm}$ in RA alone (observed changes, expressed as paired 5 years' values minus preoperative values, were $-5.8 \pm 4.1$ and $-0.2 \pm 2.3$, respectively, with $P<.001$ ). Over time, a progressive LV enlargement was observed in the RA group with values almost similar to preoperative measurements, whereas the PMA group maintained the benefit achieved soon after surgery with significantly reduced diameters at 5 years' follow-up in respect to baseline. ${ }^{1}$ The 5-year freedom from cardiac-related death rate in the PMA group was $83.3 \%$, whereas in the RA group was $79.2 \%$ $(P=.496)$. The 5-year freedom from composite cardiac endpoint in the in the PMA group was $29.2 \%$, whereas in the RA group was $6.2 \%(P=.069){ }^{1}$

\section{Symmetry of Tethering}

LVEDD, LVESD, and LVEF were evaluated among surviving patients at 5 years and were compared with the respective preoperative values (Table 2, Figure 2, A). Results indicate that patients treated with PMA had less adverse remodeling compared with patients who underwent 
TABLE 2. Echocardiographic characteristics depending on the symmetry of tethering

\begin{tabular}{|c|c|c|c|c|c|c|c|}
\hline & \multicolumn{3}{|c|}{ RA group } & \multicolumn{3}{|c|}{ PMA group } & \multirow{2}{*}{$\begin{array}{c}P \text { value } \\
\text { between delta }\end{array}$} \\
\hline & Preop, $\mathbf{N}=34$ & $5 \mathrm{y}, \mathrm{N}=34$ & Delta & Preop, $\mathbf{N}=\mathbf{3 7}$ & $5 \mathrm{y}, \mathrm{N}=\mathbf{3 7}$ & Delta & \\
\hline \multicolumn{8}{|l|}{ LVEDD } \\
\hline Symmetric tethering & $61.7 \pm 2.7(12)$ & $62.2 \pm 3.2$ & $0.5 \pm 0.6(P=.410)$ & $64.1 \pm 2.9(14)$ & $60.1 \pm 6.7$ & $-4.0 \pm 4.4(P=.004)$ & .003 \\
\hline Asymmetric tethering & $60.1 \pm 3.3(22)$ & $59.8 \pm 5.0$ & $-0.3 \pm 2.5(P=.559)$ & $61.3 \pm 3.2(23)$ & $54.2 \pm 3.5$ & $-7.0 \pm 3.5(P<.001)$ & $<.001$ \\
\hline \multicolumn{8}{|c|}{ LVESD } \\
\hline Symmetric tethering & $53.2 \pm 2.7(12)$ & $51.7 \pm 3.2$ & $-1.5 \pm 2.0(P=.023)$ & $55.0 \pm 3.5(14)$ & $51.1 \pm 6.7$ & $-3.8 \pm 4.0(P=.003)$ & .079 \\
\hline Asymmetric tethering & $51.0 \pm 3.3(22)$ & $49.4 \pm 4.7$ & $-1.6 \pm 2.4(P=.005)$ & $52.0 \pm 3.1(23)$ & $44.7 \pm 3.7$ & $-7.3 \pm 3.6(P<.001)$ & $<.001$ \\
\hline \multicolumn{8}{|c|}{ LVEF } \\
\hline Symmetric tethering & $36.3 \pm 3.6(12)$ & $38.2 \pm 1.9$ & $1.8 \pm 4.0(P=.140)$ & $33.4 \pm 3.2(14)$ & $39.9 \pm 5.0$ & $6.5 \pm 4.2(P<.001)$ & .008 \\
\hline Asymmetric tethering & $37.9 \pm 2.5(22)$ & $40.8 \pm 4.4$ & $2.9 \pm 4.4(P=.007)$ & $36.4 \pm 6.0(23)$ & $46.6 \pm 5.1$ & $10.2 \pm 6.2(P<.001)$ & $<.001$ \\
\hline
\end{tabular}

the RA approach, both in case of symmetric and asymmetric tethering. More interestingly, patients with preoperative asymmetric tethering treated with PMA had almost a 2-fold reduction in ventricular diameters $(P=.028$ for LVEDD, $P=.009$ for LVESD) and a 1.5-fold increase in LV function $(P=.056)$ compared

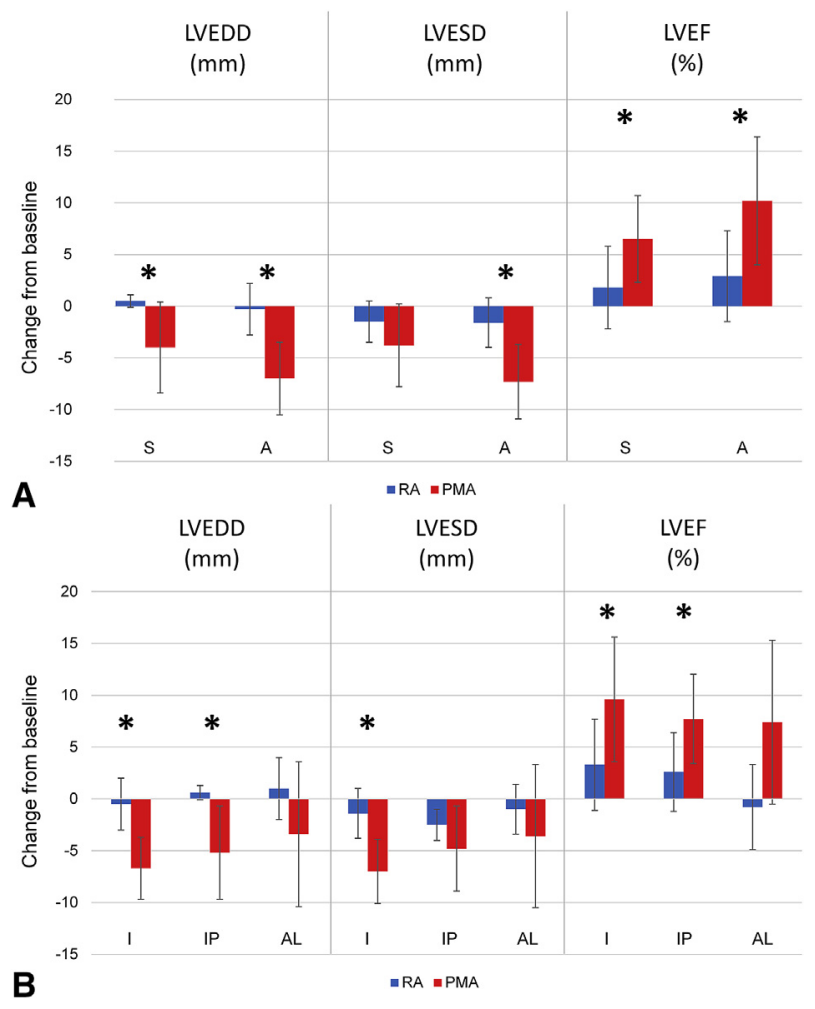

FIGURE 2. Change from baseline in echocardiographic characteristics depending on symmetry of tethering (A) or regional wall motion abnormality (B). *Difference is statistically significant with $P<.05$. $L V E D D$, Left ventricular end-diastolic diameter; $L V E S D$, left ventricular end-systolic diameter; $L V E F$, left ventricular ejection fraction; $S$, symmetric tethering; $A$, asymmetric tethering; $I$, inferior; $I P$, inferoposterior; $A L$, anterolateral. with patients with symmetric tethering treated with the same approach.

Table 3 indicates that among patients with asymmetric tethering, recurrent moderate-to-severe MR was less frequent in case of subvalvular surgery; recurrent MR was observed in $54.5 \%$ in the RA group and $26.1 \%$ in the PMA group $(P=.051)$. No statistically significant differences were observed among patients with symmetric tethering, even though recurrent MR was observed more frequently in the RA group $(P=.126)$.

\section{Regional Wall Motion Abnormalities}

LV diameters and function were evaluated at the end of the follow-up and compared with preoperative values depending on regional wall motion abnormalities (Table 4, Figure 2, B). Among patients with impaired kinesis in the inferior or in the inferoposterior segments, PMA was able to restore an adequate geometry of the left ventricle by reducing LVEDD $(P<.001$ and .002 , respectively) and improving the $\operatorname{LVEF}(P<.001$ and .022 , respectively); however, in case of abnormalities in the motion of the anterolateral wall, PMA seem to exert no additional benefit over RA associated with CABG when we considered LV remodeling and function $(P=.235$ for

TABLE 3. Recurrence of moderate-to-severe mitral regurgitation at 5 years

\begin{tabular}{lccc}
\hline & RA group, $\mathbf{N}=\mathbf{3 4}$ & PMA group, $\mathbf{N}=\mathbf{3 7}$ & $\boldsymbol{P}$ value \\
\hline $\begin{array}{l}\text { Overall } \\
\text { Tethering }\end{array}$ & $19 / 34(55.9 \%)$ & $10 / 37(27.0 \%)$ & .013 \\
$\quad$ & & & \\
$\quad$ Symmetric & $7 / 12(58.3 \%)$ & $4 / 14(28.6 \%)$ & .126 \\
$\quad$ Asymmetric & $12 / 22(54.5 \%)$ & $6 / 23(26.1 \%)$ & .051 \\
Regional wall motion abnormality & & \\
$\quad$ Inferior & $12 / 21(57.1 \%)$ & $5 / 23(21.7 \%)$ & .016 \\
$\quad$ Inferoposterior & $4 / 8(50.0 \%)$ & $3 / 9(33.3 \%)$ & .486 \\
Anterolateral & $3 / 5(60.0 \%)$ & $2 / 5(40.0 \%)$ & .527 \\
\hline
\end{tabular}

$R A$, Restrictive annuloplasty; PMA, papillary muscle approximation. 
TABLE 4. Echocardiographic characteristics depending on the regional wall motion abnormality

\begin{tabular}{|c|c|c|c|c|c|c|c|}
\hline & \multicolumn{3}{|c|}{ RA group } & \multicolumn{3}{|c|}{ PMA group } & \multirow{2}{*}{$\begin{array}{c}P \text { value } \\
\text { between delta }\end{array}$} \\
\hline & Preop, $N=34$ & $5 \mathrm{y}, \mathrm{N}=34$ & Delta & Preop, $\mathbf{N}=\mathbf{3 7}$ & $5 \mathrm{y}, \mathrm{N}=37$ & Delta & \\
\hline \multicolumn{8}{|l|}{ LVEDD } \\
\hline Inferior & $59.7 \pm 3.1(21)$ & $59.2 \pm 4.8$ & $-0.5 \pm 2.5(P=.356)$ & $61.0 \pm 2.5(23)$ & $54.3 \pm 3.6$ & $-6.7 \pm 3.0(P<.001)$ & $<.001$ \\
\hline Inferoposterior & $61.4 \pm 2.9(8)$ & $62.0 \pm 3.3$ & $0.6 \pm 0.7(P=.049)$ & $63.2 \pm 3.3(9)$ & $58.0 \pm 7.1$ & $-5.2 \pm 4.5(P=.008)$ & .002 \\
\hline Anterolateral & $63.6 \pm 2.3(5)$ & $64.6 \pm 1.5$ & $1.0 \pm 3.0(P=.497)$ & $67.0 \pm 2.3(5)$ & $63.6 \pm 4.9$ & $-3.4 \pm 7.0(P=.342)$ & .235 \\
\hline \multicolumn{8}{|l|}{ LVESD } \\
\hline Inferior & $50.5 \pm 2.8(21)$ & $49.1 \pm 4.8$ & $-1.4 \pm 2.4(P=.017)$ & $51.7 \pm 2.4(23)$ & $44.7 \pm 3.8$ & $-7.0 \pm 3.1(P<.001)$ & $<.001$ \\
\hline Inferoposterior & $53.7 \pm 3.0(8)$ & $51.2 \pm 2.6$ & $-2.5 \pm 1.5(P=.002)$ & $53.9 \pm 3.9(9)$ & $49.1 \pm 7.1$ & $-4.8 \pm 4.1(P=.008)$ & .158 \\
\hline Anterolateral & $54.4 \pm 2.6(5)$ & $53.4 \pm 2.4$ & $-1.0 \pm 2.4(P=.413)$ & $58.2 \pm 2.3(5)$ & $54.6 \pm 4.9$ & $-3.6 \pm 6.9(P=.311)$ & .453 \\
\hline \multicolumn{8}{|l|}{ LVEF } \\
\hline Inferior & $37.8 \pm 2.5(21)$ & $41.1 \pm 4.2$ & $3.3 \pm 4.4(P=.003)$ & $36.8 \pm 5.4(23)$ & $46.3 \pm 5.4$ & $9.6 \pm 6.0(P<.001)$ & $<.001$ \\
\hline Inferoposterior & $35.5 \pm 3.5(8)$ & $38.1 \pm 2.6$ & $2.6 \pm 3.8(P=.093)$ & $33.8 \pm 3.4(9)$ & $41.4 \pm 5.7$ & $7.7 \pm 4.3(P<.001)$ & .022 \\
\hline Anterolateral & $38.2 \pm 3.5(5)$ & $37.4 \pm 1.5$ & $-0.8 \pm 4.1(P=.689)$ & $31.0 \pm 5.0(5)$ & $38.4 \pm 3.3$ & $7.4 \pm 7.9(P=.105)$ & .074 \\
\hline
\end{tabular}

LVEDD, $P=.453$ for LVESD, $P=.074$ for LVEF); however, the limited number of patients in this subgroup may have underestimated the benefit of subvalvular surgery in this condition.

Among patients with inferior wall motion abnormality, the recurrence of MR was more common in the RA group compared with the PMA group $(57.1 \%$ vs $21.7 \%$, $P=.016$ ) (Table 3). Inferoposterior and anterolateral wall motion abnormalities showed no significant differences in the recurrence of MR between the 2 surgical groups ( $P=.486$ and .527 , respectively).

Overall mortality, reoperations, and composite cardiac endpoint over the follow-up for both groups with regard to tethering symmetry and regional wall motion abnormality are presented in Table 5. Despite no differences in overall mortality and in the composite cardiac endpoint, PMA proved to reduce reoperation rate among patients with symmetric tethering $(P=.053)$ and with inferoposterior dyskinesia $(P=.048)$ (Figures E1-E3).

\section{DISCUSSION}

The preferred surgical strategy for moderate and severe IMR is not established. ${ }^{17-21}$ There are many experimental studies supporting the benefits of adding subvalvular repair to undersizing annuloplasty ${ }^{1,15,22,23}$; of these, many have refuted the benefits of valve repair ${ }^{2}$ and others

TABLE 5. Overall mortality, reoperations, and composite cardiac endpoint

\begin{tabular}{lccc}
\hline & RA group, N=48 & PMA group, N $=\mathbf{4 8}$ & P value (log rank) \\
\hline Overall mortality & & & \\
Symmetric tethering & $6 / 18(33.3 \%)$ & $5 / 19(26.3 \%)$ & .672 \\
Asymmetric tethering & $8 / 30(26.7 \%)$ & $6 / 29(20.7 \%)$ & .589 \\
Inferior wall dyskinesia & $8 / 29(27.6 \%)$ & $6 / 29(20.7 \%)$ & .539 \\
Inferoposterior wall dyskinesia & $2 / 10(20.0 \%)$ & $2 / 11(18.2 \%)$ & .998 \\
Anterolateral wall dyskinesia & $4 / 9(44.4 \%)$ & $3 / 8(37.5 \%)$ & .778 \\
Reoperation & & & .053 \\
Symmetric tethering & $3 / 18(16.7 \%)$ & $0 / 19(0.0 \%)$ & .746 \\
Asymmetric tethering & $4 / 30(13.3 \%)$ & $3 / 29(10.3 \%)$ & .987 \\
Inferior wall dyskinesia & $3 / 29(10.3 \%)$ & $0 / 11(0.0 \%)$ & .048 \\
Inferoposterior wall dyskinesia & $3 / 10(30.0 \%)$ & $0 / 8(0.0 \%)$ & .317 \\
Anterolateral wall dyskinesia & $1 / 9(11.1 \%)$ & $12 / 19(63.1 \%)$ & .065 \\
Composite cardiac endpoint & & $22 / 29(75.9 \%)$ & .493 \\
Symmetric tethering & $17 / 18(94.4 \%)$ & $22 / 29(75.9 \%)$ & .601 \\
Asymmetric tethering & $28 / 30(93.3 \%)$ & $6 / 11(54.5 \%)$ & .152 \\
Inferior wall dyskinesia & $27 / 29(93.1 \%)$ & $6 / 8(75.0 \%)$ & .200 \\
Inferoposterior wall dyskinesia & $9 / 10(90.0 \%)$ & $9 / 9(100.0 \%)$ & \\
Antero-lateral wall dyskinesia & & & \\
\hline
\end{tabular}

Numbers indicate the events and patients at risk in each group. $P$ value is calculated from Kaplan Meier analysis with a log rank test. $R A$, Restrictive annuloplasty; $P M A$, papillary muscle approximation. 
have neutral findings. ${ }^{24}$ Divergence in treatment and difference in clinical outcomes state that current surgical approaches to IMR have not led to a radical and definitive solution of this complex pathology. ${ }^{1,2,15,20,22,25}$ Rather, we observe a metamorphosis of IMR in a chronic condition characterized by recurrence of disease a few years after treatment. ${ }^{24,26}$ Two-year results of the Cardiothoracic Surgical Trials Network (CTSN) revealed a reported incidence of moderate-to-severe MR ranging around $55 \%$,with adverse LV remodeling and worsening functional status, ${ }^{2,14,20}$ which also have significant societal implications. ${ }^{27,28}$

In our recently published study, we evaluated the efficacy and safety of adding PMA to undersizing mitral annuloplasty associated with CABG in the restoration of function of subvalvular apparatus, emphasizing the effect of surgically induced geometric changes in the LV and MV relationships on the repair. ${ }^{1}$ The study, which included patients with severe IMR, coronary artery disease eligible for surgical revascularization, global LV dysfunction, and regional wall motion abnormalities, revealed that the rate of reoperation from recurrence MR at 5 years tended to be lower among patients who underwent PMA surgery compared with patients those who received an annularonly approach, without reaching a statistical significance $(6.2 \%$ vs $14.6 \%, P=.181)$.

Moreover, despite the beneficial effect on LV remodeling and mitral configuration, adding subvalvular apparatus surgery to the standard RA approach did not produce a longterm advantage in survival or functional status, leaving us to question the coexistence of "other" unconsidered or unaddressed factors playing a determinant role in the final outcome of the reparative procedure. Long-term outcomes after MV surgery in IMR have been shown to be dependent mainly on postprocedure $\mathrm{LV}$ remodeling over time. ${ }^{1,2} \mathrm{LV}$ remodeling, as measured by means of the LVEDD (the primary endpoint in our trial), is a prognostic marker for patients with IMR, and subvalvular repair has been associated with improved outcomes in patients with IMR by counteracting LV adverse remodeling. ${ }^{1}$ Moreover, tethering symmetry and wall motion abnormalities have a pivotal role in IMR and may serve as factors to provide a tailored surgical approach. ${ }^{10,12,29}$ Our objective was to perform a subanalysis of the results of our trial to elucidate the value of PMA in those subcategories of patients aiming to elaborate a potential decision algorithm. The goal is to describe the best operative strategy that should be followed according to the preoperative status.

\section{Postoperative MV Configuration and Recurrent MR}

Beside the limitations related to the sample size and the reduced statistical power of the study for binary events, the major findings of this subanalysis can be summarized as follows: (1) PMA improved ventricular remodeling and function in both preoperative symmetric and asymmetric tethering and this effect was more significant in the latter case; (2) PMA allowed a more effective recovery of LV dimension and function in case of inferior wall preoperative dyskinesia, whereas it did not produce additional benefit in anterolateral wall dysfunction; (3) PMA prevented moderate-to-severe MR recurrence in asymmetric tethering and in patients with preoperative inferior wall impairment; and (4) PMA reduced the rate of reoperation among patients with symmetric tethering and inferoposterior dyskinesia.

Although no difference in mortality was found in relation to the symmetry of tethering or regional wall dysfunction, the results of this study might allow us to speculate that patients with symmetric and asymmetric tethering and with localized inferior wall motion abnormalities might benefit from a combined annular and subvalvular repair strategy in combination with a total revascularization.

Reoperation rate at 5 years was about $50 \%$ lower among patients receiving PMA than among patients treated with RA alone, in addition to CABG. Similarly, incidence of MR recurrence was significantly lower when the PMA approach was used in comparison with the annuloplasty alone in both conditions of tethering. Although statistical significance was not achieved among patients with symmetric tethering, we might reliably speculate that this was an effect of the limited number of patients in this group, as testified by the numerical difference of patients experiencing these complications (Table 3). A potential explanation of those findings might be the ability of PMA to restore the overall MV geometry and PM function in MV physiology, as testified by several clinical and echocardiography investigations pointing at the pivotal role of PM systolic dyssynchrony in the prediction of significant postoperative MR recurrence. ${ }^{6,8,29}$

In this context, the most striking finding is the positive effect exerted by PMA in conditions of preoperative symmetric tethering, which has been considered a pattern of advanced stage in the ischemic disease caused by predominant vectorial lateral and apical displacement of PM with traction on both leaflets and dilated-dysfunctional LV. This preoperative pattern has not been considered amenable to a simple RA. ${ }^{10}$ This concept also has been stressed in several studies from Gelsomino and colleagues, ${ }^{12,13}$ in which they demonstrated that symmetric tethering is a strong negative predictor of $\mathrm{LV}$ reverse remodeling after annuloplasty. PMA corrected the posterior apical and lateral PM displacement occurring in symmetric tethering and the predominant posterior displacement causing the asymmetric tethering, providing an adequate solution in both these circumstances.

In agreement with previous studies, ${ }^{12,13,30}$ we also found improved LV remodeling and recurrence rate or MR in the 
asymmetric tethering group undergoing PMA; however, the symmetric group also significantly benefited from PMA in terms of reverse remodeling, LV function, and reoperation. Restoration of an adequate ventricular geometry with subsequent effect on both the anterior and posterior leaflet might justify the superiority of the combined PMA approach over the annuloplasty only.

Nevertheless, the possibility to achieve geometrical restoration is strictly intertwined with the regional ventricular functional status, which is responsible for PM synchrony and function. In this study, we demonstrated that specific regional alterations of normal LV kinesis profoundly affect the outcome of the valvular and subvalvular repair. Indeed, although the dyskinesia of the inferior wall can be accommodated by the approximation of the PM, dysfunction of the anterior or lateral wall creates an excessive degree of lateral displacement and PM dyssynchrony, which cannot be compensated by this surgical approach. Preoperative anterolateral wall dyskinesia was indeed associated with high mortality and adverse cardiac outcomes, and we might speculate that a preoperative asymmetrical tethering pattern would be even more affected by this regional dysfunction.

Clearly, these considerations cannot neglect the mandatory need for an accompanying total revascularization in all patients with IMR. Myocardial revascularization is indeed a basic tenet in IMR surgery and grafting all the dysfunctioning territories is required to optimize outcomes, as indirectly demonstrated by this subanalysis. In support of this hypothesis is the central role of total myocardial revascularization over the MV repair techniques described by Michler and colleagues ${ }^{25}$ in case of a moderate degree of IMR. Additional support for this idea is provided by the finding of a high incidence of MR recurrence in the CTSN trial for severe IMR, in which $30 \%$ of the patients did not receive myocardial revascularization. ${ }^{2}$

\section{Surgical Strategy}

The imbalance between the forces exerted on the annulus and the displacement vectors of the PM drives the long-term outcomes and durability of the repair. A $30 \%$ approximation of the PM in this study was able to adequately restore the geometrical relationships within the $\mathrm{LV}$ and redistribute conveniently the forces on the mitral annulus and leaflets. In this context, we already have proposed a reinforcement of the posterior annulus by means of a double row of overlapping sutures with the aim of reducing the tension on the portion of the annulus experiencing the greatest stress. ${ }^{21}$ We acknowledge the option of PM relocation in IMR surgery ${ }^{31,32}$; however, we believe that this technique does not address the multidirectional displacement and migration of the PM and might result in increased tension at the level of the posterior trigone and PM, with potential adverse biomechanical effects. Indeed, it has been shown that the relocation of the PM might be associated with a restrictive effect on the MV if directed only to the posterior leaflet as inducing a tilting effect on the posterior annulus and augmenting its posterior tethering. ${ }^{31}$

To this extent, in the largest series of Fattouch and colleagues $^{32}$ the PM relocation was effective only in association with a nonrestrictive annuloplasty. We acknowledge the overall high incidence of moderate-tosevere MR recurrence in the study. An explanation underlying this finding is the complex relationship between closing and tethering forces and the progression of LV remodeling over time. Especially in cases of anterolateral wall abnormalities, PMA was not able to interrupt or revert the phenomenon of adverse LV remodeling. The persistence of elevated LVEDD and LVESD with dilated LV cavity determines increased endocavitary shear stresses and might have created a detrimental effect on the repair and even the loss of adhesion between the muscles and the Gore-Tex band.

Considering this complexity together with the variability of the characteristics of the regurgitant jet found in patients with recurrent MR, we have developed a mathematical model that describes the biomechanics of the MV apparatus (including factors such as chordae viscosity, chordae Young modulus, etc) with the final aim of elaborating a decisional algorithm to support the surgical choices in IMR treatment $^{33}$; however, compared with the results of the CTSN trial, PMA combined with RA produced a significantly improved rate of reoperation to the group receiving annuloplasty only in the CTSN trial.

PMs exert an important role in the maintenance of mitral geometry, and we believe that a comprehensive strategy that includes not only the annular but also the subvalvular part of the mitral apparatus represents the most appropriate approach to treat IMR. Indeed, this technique provides a more complete and "holistic" approach to the problem of IMR. The results of this study together with the work of other investigators in this field ${ }^{8}$ might potentially induce others to reconsider the major trials published that demand another type of surgical comparison: a "complete mitral repair" (ie, involving both the valvular and subvalvular apparatus) versus chordal-sparing mitral replacement.

Although not effectively comparable considering the study design and the different duration of follow-up, a paradoxical comparison between the current results by the CTSN trial on chordal sparring mitral replacement and the combination of PMA and RA described in this manuscript would show interesting results. If comparing the data at 2 years' follow-up in the CTSN trial with the actuarial results at 2 years in our study, the mortality rate would be lower in the PMA group than in the replacement group (replacement $23.3 \%$ vs PMA $16.7 \%$ ). Similarly, the 
occurrence of major adverse cardiac and cerebrovascular events would be $39.6 \%$ in the PMA group versus $42.4 \%$ in the valve replacement group, and the incidence of stroke would be slightly lower in the PMA group (PMA $4.1 \%$ vs $5.6 \%$ in replacement group). However, recurrence of moderate-to-severe MR at 2 years in the mitral replacement group of the CTSN trial was $3.8 \%$, whereas in the PMA group it would be $15 \%$ at the same time point. Similarly, the reoperation rate for mitral replacement in the CTSN trial at 2 years was as low as $0.8 \%$ compared with $2.1 \%$ in the PMA group of the current study at the same time point. Finally, there was a statistical significant increase in aortic crossclamp time and cardiopulmonary bypass time in the PMA group but the procedure required effectively around 10 to 15 minutes more to be performed in respect to the RA only.

\section{Limitations}

Among the limitations of this study, the authors already have acknowledged the fact that the primary endpoint of the study relied on an echocardiographic measure of LV remodeling rather than a clinical outcome (such as mortality); however, such a randomized trial would have required a number of patients to achieve statistical power would have required too much time to enroll an adequate number of patients. Similarly, the region of wall motion abnormality was categorized as inferior, inferoposterior, or anterolateral, and the conventional division in 16 segments used in transthoracic echocardiography would have required a far greater sample size, which was not enrolled for the study, considering its primary endpoint.

Also, this study aimed to identify a difference in the surgical efficacy of the combined annular and subvalvular approach to consider a possible step change in the current surgical practice in particular subgroup of patients. Therefore, a routinely and universally used and recognized echocardiographic set of parameters seemed the best-suited approach in this setting. The authors are aware, however, of the possible operator-dependent fluctuations in data interpretation when transthoracic echocardiography is used. In this study, 2 blinded experienced cardiologists performed all the echocardiograms, providing sufficient reliability of the results. Also, under- or overestimation of ejection fraction might occur in case of MR, but these parameters have been adjusted in consideration of the transmitral gradient and the inflow velocity. To circumvent these issues, however, the use of computed tomography or magnetic resonance imaging should be advocated to evaluate the MV apparatus in detail.

Finally, data on tenting height in addition to the data on interpapillary muscle distance and tethering angles (see original report of PMA trial) ${ }^{1}$ might have introduced other potential variables useful in decision-making. The study was designed and powered initially to describe different outcomes, but other post-hoc analysis might be performed in the near future to elucidate this point. The lack of studies comparing the biomechanical stress applied to MV annular and subvalvular apparatus after each repair procedure does not allow a comparison among surgical strategies. Therefore, the choice for a particular technique relies generally on surgeon's preference rather than evidence. ${ }^{34}$ Future studies will address those issues, allowing a more detailed evaluation of each procedure.

\section{CONCLUSIONS}

In conclusion, the results of this subanalysis confirm that both preoperative patterns of symmetrical and asymmetrical tethering might be considered an indication for adjunctive PMA in combination with the standard RA and $\mathrm{CABG}$ approach in IMR as guaranteeing significantly better outcomes. The presence of inferior dyskinesia should encourage PMA, although this technique may not produce additional benefit in cases of anterolateral dysfunction.

\section{Conflict of Interest Statement}

Authors have nothing to disclose with regard to commercial support.

\section{References}

1. Nappi F, Lusini M, Spadaccio C, Nenna A, Covino E, Acar C, et al. Papillary muscle approximation versus restrictive annuloplasty alone for severe ischemic mitral regurgitation: a randomized trial. J Am Coll Cardiol. 2016;24:2334-46.

2. Goldstein D, Moskowitz AJ, Gelijns AC, Ailawadi G, Parides MK, Perrault LP, et al. Two-year outcomes of surgical treatment of severe ischemic mitral regurgitation. N Engl J Med. 2016;374:344-53.

3. Tibayan FA, Rodriguez F, Zasio MK, Bailey L, Liang D, Daughters GT, et al. Geometric distortions of the mitral valvular-ventricular complex in chronic ischemic mitral regurgitation. Circulation. 2003;108(suppl 1):II116-21.

4. Tibayan FA, Rodriguez F, Langer F, Liang D, Daughters GT, Ingels NB Jr, et al. Undersized mitral annuloplasty alters left ventricular shape during acute ischemic mitral regurgitation. Circulation. 2004;110:II98-102.

5. Langer F, Rodriguez F, Ortiz S, Cheng A, Nguyen TC, Zasio MK, et al. Subvalvular repair: the key to repairing ischemic mitral regurgitation? Circulation. 2005; 112:1383-9.

6. Otsuji Y, Levine RA, Takeuchi M, Sakata R, Tei C. Mechanism of ischemic mitral regurgitation. J Cardiol. 2008;51:145-56.

7. Otsuji Y, Handschumacher MD, Liel-Cohen N, Tanabe H, Jiang L, Schwammenthal E, et al. Mechanism of ischemic mitral regurgitation with segmental left ventricular dysfunction: three-dimensional echocardiographic studies in models of acute and chronic progressive regurgitation. J Am Coll Cardiol. 2001;37:641-8.

8. Kalra K, Wang Q, McIver BV, Shi W, Guyton RA, Sun W, et al. Temporal changes in interpapillary muscle dynamics as an active indicator of mitral valve and left ventricular interaction in ischemic mitral regurgitation. J Am Coll Cardiol. 2014;64:1867-79.

9. Flynn M, Curtin R, Nowicki ER, Rajeswaran J, Flamm SD, Blackstone EH, et al. Regional wall motion abnormalities and scarring in severe functional ischemic mitral regurgitation: a pilot cardiovascular magnetic resonance imaging study J Thorac Cardiovasc Surg. 2009;137:1063-70.e2.

10. van Garsse L, Gelsomino S, Cheriex E, Luca F, Rao CM, Parise O, et al. Tethering symmetry reflects advanced left ventricular mechanical dyssynchrony in patients with ischemic mitral regurgitation undergoing restrictive mitral valve repair. Ann Thorac Surg. 2012;94:1418-28.

11. Zeng X, Nunes MC, Dent J, Gillam L, Mathew JP, Gammie JS, et al. Asymmetric versus symmetric tethering patterns in ischemic mitral regurgitation: geometric differences from three-dimensional transesophageal echocardiography. J Am Soc Echocardiogr. 2014;27:367-75. 
12. Gelsomino S, Lorusso R, De Cicco G, Bille G, Caciolli S, Rostagno C, et al. Does preoperative tethering symmetry affect left ventricular reverse remodeling after restrictive annuloplasty? Int J Cardiol. 2010;141:182-91.

13. Gelsomino S, Lorusso R, Caciolli S, Capecchi I, Rostagno C, Chioccioli M, et al. Insights on left ventricular and valvular mechanisms of recurrent ischemic mitral regurgitation after restrictive annuloplasty and coronary artery bypass grafting. J Thorac Cardiovasc Surg. 2008;136:507-18.

14. Smith PK, Michler RE, Woo YJ, Alexander JH, Puskas JD, Parides MK, et al. Design, rationale, and initiation of the Surgical Interventions for Moderate Ischemic Mitral Regurgitation Trial: a report from the Cardiothoracic Surgical Trials Network. J Thorac Cardiovasc Surg. 2012;143:111-7. 117.e1.

15. Shudo Y, Matsumiya G, Sakaguchi T, Miyagawa S, Yoshikawa Y, Yamauchi T, et al. Assessment of changes in mitral valve configuration with multidetector computed tomography: impact of papillary muscle imbrication and ring annuloplasty. Circulation. 2010;122:S29-36.

16. Zoghbi WA, Chambers JB, Dumesnil JG, Foster E, Gottdiener JS, Grayburn PA, et al. Recommendations for evaluation of prosthetic valves with echocardiography and Doppler ultrasound: a report From the American Society of Echocardiography's Guidelines and Standards Committee and the Task Force on Prosthetic Valves, developed in conjunction with the American College of Cardiology Cardiovascular Imaging Committee, Cardiac Imaging Committee of the American Heart Association, the European Association of Echocardiography, a registered branch of the European Society of Cardiology, the Japanese Society of Echocardiography and the Canadian Society of Echocardiography, endorsed by the American College of Cardiology Foundation, American Heart Association, European Association of Echocardiography, a registered branch of the European Society of Cardiology, the Japanese Society of Echocardiography, and Canadian Society of Echocardiography. J Am Soc Echocardiogr. 2009;22:975-1014; quiz 82-4.

17. Kron IL, Green GR, Cope JT. Surgical relocation of the posterior papillary muscle in chronic ischemic mitral regurgitation. Ann Thorac Surg. 2002;74: $600-1$.

18. Hvass U, Tapia M, Baron F, Pouzet B, Shafy A. Papillary muscle sling: a new functional approach to mitral repair in patients with ischemic left ventricular dysfunction and functional mitral regurgitation. Ann Thorac Surg. 2003;75: 809-11.

19. Rama A, Nappi F, Praschker BG, Gandjbakhch I. Papillary muscle approximation for ischemic mitral valve regurgitation. J Card Surg. 2008;23:733-5.

20. Acker MA, Parides MK, Perrault LP, Moskowitz AJ, Gelijns AC, Voisine P, et al. Mitral-valve repair versus replacement for severe ischemic mitral regurgitation. N Engl J Med. 2014;370:23-32.

21. Nappi F, Spadaccio C, Chello M, Lusini M, Acar C. Double row of overlapping sutures for downsizing annuloplasty decreases the risk of residual regurgitation in ischaemic mitral valve repair. Eur J Cardiothorac Surg. 2016;49:1182-7.

22. Fattouch K, Guccione F, Sampognaro R, Panzarella G, Corrado E, Navarra E, et al. POINT: efficacy of adding mitral valve restrictive annuloplasty to coronary artery bypass grafting in patients with moderate ischemic mitral valve regurgitation: a randomized trial. J Thorac Cardiovasc Surg. 2009;138:278-85.
23. Fattouch K, Lancellotti P, Castrovinci S, Murana G, Sampognaro R, Corrado E, et al. Papillary muscle relocation in conjunction with valve annuloplasty improve repair results in severe ischemic mitral regurgitation. J Thorac Cardiovasc Surg. 2012;143:1352-5.

24. Kron IL, Hung J, Overbey JR, Bouchard D, Gelijns AC, Moskowitz AJ, et al. Predicting recurrent mitral regurgitation after mitral valve repair for severe ischemic mitral regurgitation. J Thorac Cardiovasc Surg. 2015;149: 752-61.e1.

25. Michler RE, Smith PK, Parides MK, Ailawadi G, Thourani V, Moskowitz AJ, et al. Two-year outcomes of surgical treatment of moderate ischemic mitral regurgitation. N Engl J Med. 2016;374:344-53.

26. Bolling SF, Deeb GM, Brunsting LA, Bach DS. Early outcome of mitral valve reconstruction in patients with end-stage cardiomyopathy. J Thorac Cardiovasc Surg. 1995;109:676-82; discussion 82-3.

27. Mozaffarian D, Benjamin EJ, Go AS, Arnett DK, Blaha MJ, Cushman M, et al. Heart Disease and Stroke Statistics-2016 Update: a report from the American Heart Association. Circulation. 2016;133:e38-360.

28. Bursi F, Enriquez-Sarano M, Nkomo VT, Jacobsen SJ, Weston SA, Meverden RA, et al. Heart failure and death after myocardial infarction in the community: the emerging role of mitral regurgitation. Circulation. 2005;111: 295-301.

29. Kim K, Kaji S, An Y, Yoshitani H, Takeuchi M, Levine RA, et al. Mechanism of asymmetric leaflet tethering in ischemic mitral regurgitation: 3D analysis with multislice CT. JACC Cardiovasc Imaging. 2012;5:230-2.

30. Agricola E, Oppizzi M, Maisano F, De Bonis M, Schinkel AF, Torracca L, et al Echocardiographic classification of chronic ischemic mitral regurgitation caused by restricted motion according to tethering pattern. Eur J Echocardiogr. 2004;5: 326-34.

31. Watanabe T, Arai H, Nagaoka E, Oi K, Hachimaru T, Kuroki H, et al. Influence of procedural differences on mitral valve configuration after surgical repair for functional mitral regurgitation: in which direction should the papillary muscle be relocated? J Cardiothorac Surg. 2014;9:185.

32. Fattouch K, Castrovinci S, Murana G, Dioguardi P, Guccione F, Nasso G, et al. Papillary muscle relocation and mitral annuloplasty in ischemic mitral valve regurgitation: midterm results. J Thorac Cardiovasc Surg. 2014;148:1947-50.

33. Nappi F, Spadaccio C, Fraldi M. Complete mitral valve repair: the new direction of travel. Towards geometry-based biomechanical modeling. J Am Coll Cardiol. June 2016 [Epub ahead of print].

34. Mihos CG, Santana O. Can papillary muscle interventions improve mitral valve repair durability for ischemic mitral regurgitation? J Thorac Cardiovasc Surg. $2015 ; 150: 427-8$

Key Words: papillary muscle, mitral regurgitation, annuloplasty, approximation, ischemic mitral regurgitation, ventricular remodeling 

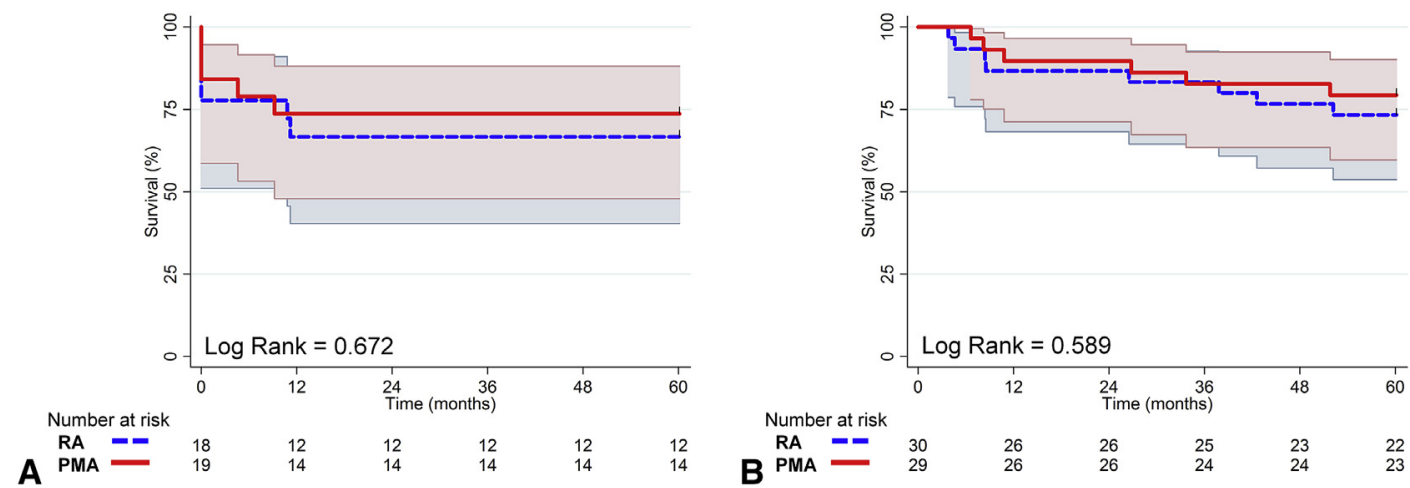

FIGURE E1. Overall mortality in patients with symmetric tethering (A) and asymmetric tethering (B).
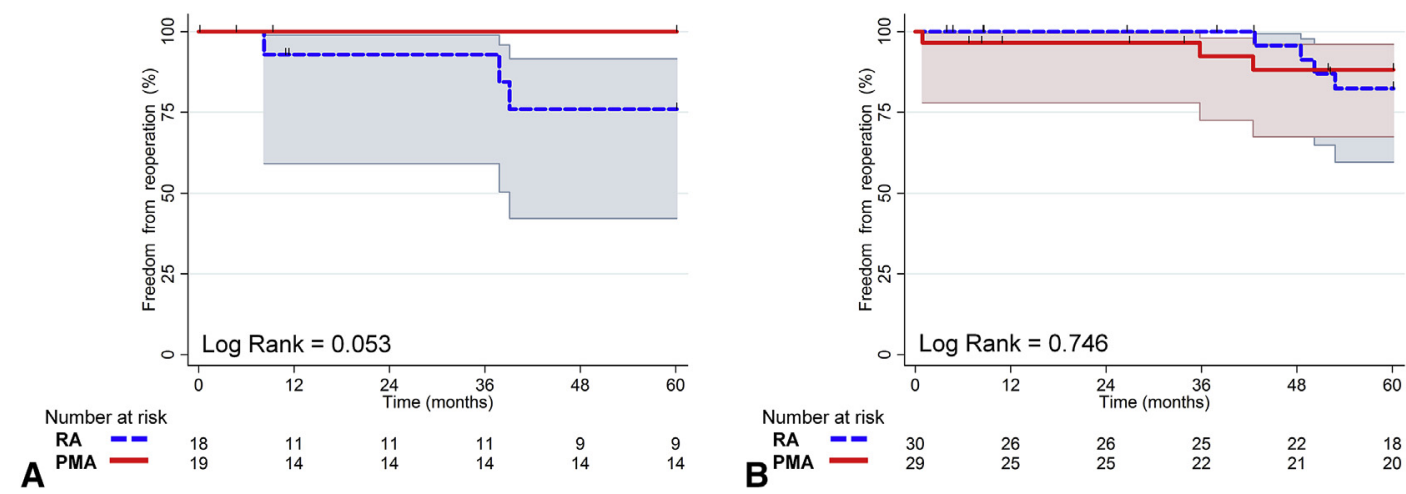

FIGURE E2. Freedom from reoperation in patients with symmetric tethering (A) and asymmetric tethering (B).
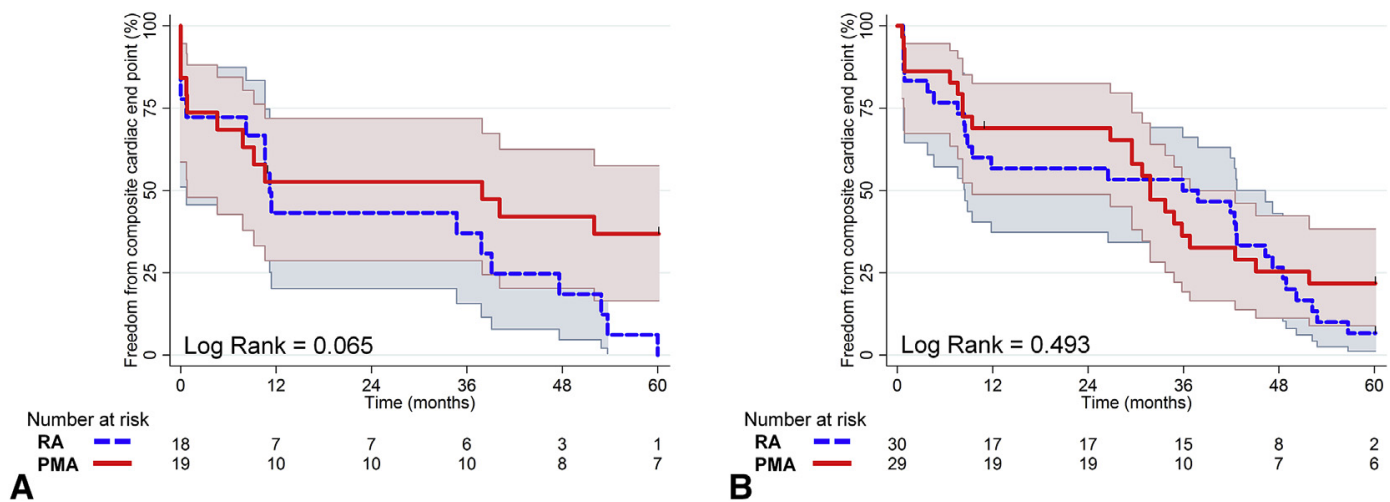

FIGURE E3. Freedom from composite cardiac endpoint in patients with symmetric tethering (A) and asymmetric tethering (B). 
TABLE E1. Subanalysis variables

\begin{tabular}{lcc}
\hline \multicolumn{1}{c}{ Variable } & t & $\boldsymbol{P}$ value \\
\hline Symmetric tethering & $\mathbf{2 . 0 0}$ & $\mathbf{. 0 5 0}$ \\
Wall motion abnormality & $\mathbf{1 . 6 2}$ & $\mathbf{. 1 1 0}$ \\
Family history of cardiovascular disease & 1.20 & .235 \\
Preoperative atrial fibrillation & -1.07 & .290 \\
Chronic kidney disease & 1.02 & .313 \\
Preoperative ejection fraction & 1.00 & .319 \\
Age & 0.98 & .330 \\
Male sex & 0.61 & .542 \\
Preoperative tenting height & 0.60 & .554 \\
Diabetes & 0.51 & .611 \\
Preoperative pulmonary artery systolic pressure & 0.50 & .621 \\
Preoperative interpapillary distance & -0.47 & .637 \\
Hypertension & 0.44 & .663 \\
Preoperative tenting area & 0.28 & .784 \\
Early treatment & -0.15 & .879 \\
Dyslipidemia & -0.05 & .958 \\
\hline
\end{tabular}

Linear regression analysis: the primary endpoint of the study (left ventricular end diastolic diameter, absolute difference at 5 years from baseline) has been considered as the dependent variable; other variables have been evaluated after adjustment for treatment group (PMA vs RA). Variables in bold with a $P$ value less than .200 have been considered for the subanalysis discussed in the manuscript.

TABLE E2. Longitudinal mixed model

\begin{tabular}{|c|c|c|c|c|c|}
\hline \multirow[b]{2}{*}{ PMA group effect } & \multicolumn{2}{|c|}{ Tethering } & \multicolumn{3}{|c|}{ Regional wall motion abnormality } \\
\hline & Symmetric & Asymmetric & Inferior & Inferoposterior & Anterolateral \\
\hline \multicolumn{6}{|l|}{ LVEDD } \\
\hline Coefficient & -2.07 & -3.00 & -2.74 & -2.66 & -2.13 \\
\hline $95 \% \mathrm{CI}$ & $-2.87 /-1.27$ & $-3.77 /-2.24$ & $-3.36 /-2.12$ & $-3.78 /-1.54$ & $-4.41 / 0.1$ \\
\hline$P$ value & $P<.001$ & $P<.001$ & $P<.001$ & $P<.001$ & $P=.064$ \\
\hline \multicolumn{6}{|l|}{ LVESD } \\
\hline Coefficient & -1.85 & -2.75 & -2.61 & -1.81 & -2.33 \\
\hline $95 \% \mathrm{CI}$ & $-2.60 /-1.10$ & $-3.47 /-2.03$ & $-3.20 /-2.02$ & $-2.70 /-0.92$ & $-4.53 /-0.14$ \\
\hline$P$ value & $P<.001$ & $P<.001$ & $P<.001$ & $P<.001$ & $P=.039$ \\
\hline \multicolumn{6}{|l|}{ LVEF } \\
\hline Coefficient & 2.10 & 4.25 & 3.87 & 2.56 & 2.70 \\
\hline $95 \% \mathrm{CI}$ & $1.02 / 3.19$ & $2.80 / 5.70$ & $2.52 / 5.22$ & $1.07 / 4.06$ & $-0.29 / 5.69$ \\
\hline$P$ value & $P<.001$ & $P<.001$ & $P<.001$ & $P=.002$ & $P=.074$ \\
\hline
\end{tabular}

PMA group effect compared with the RA group effect is expressed as unit change per year after surgery, depending on the symmetry of tethering or regional wall motion abnormalities. A negative value indicates a reduction after surgery, whereas a positive value represents an increase after surgery. PMA, Papillary muscle approximation; $L V E D D$, left ventricular end diastolic diameter; $C I$, confidence interval; $L V E S D$, left ventricular end systolic diameter; $L V E F$, left ventricular ejection fraction. 